\title{
REVIEW OF CURRENT EARTHQUAKE ENGINEERING RESEARCH IN NEW ZEALAND
}

\author{
P. J. Moss' 1
}

\begin{abstract}
Research currently being undertaken in Government Departments, Research organisations, and the Civil Engineering Departments in the two University Schools of Engineering is outlined. The reasearch is summarised under the headings of seismology, Engineering Seismology, Geotechnical Engineering, and Structural Analysis and Design.
\end{abstract}

\section{INTRODUCTION}

Currently, there is a large amount of earthquake engineering research underway in New Zealand covering a wide range of topics and being undertaken by Government Departments, research organisations and Civil Engineering Departments in University Schools of Engineering. Broadly speaking, this research covers the fields of Seismology, Engineering Seismology, Geotechnical Engineering and Structural Analysis and Design. This article outlines the major items of research that are currently in progress, and gives some indication of the objectives of the work.

Any inquiries about particular research should be directed to the relevant organisation at the address listed in Appendix A.

\section{SEISMOLOGY}

GEOPHYSICS DIVISION, D.S.I.R.

1 Digital Seismographs.

These are being used to progressively replace the existing analogue seismographs of the National Network. The Seismological observatory is developing its own digital recorder to meet the specific needs as no commercially available one meets these needs at an affordable price. Substantial progress has been made, particularly in the area of digital recording of semi-permanent micro-networks (see 2) where only digital seismic traces of earthquakes, identified by their spectral signature, are kept. The detection algorithm is one of the most reliable and least wasteful (fewer false alarms) that has been published. Most of

1. Bulletin Editor, and

Department of Civil Engineering,

University of Canterbury, Christchurch the software and much of the hardware developed for the micro-network recorders will be adapted to the single National Network stations.

\section{Micro-networks.}

A diversion of effort from the single station to micro-networks was required because of demand for a number of such networks and efficient recording and processing of their data. Within the next few months, new networks will be installed in Hawke's Bay and around the clyde dam site, and the recording system of the Taupo Network will be upgraded. The Wellington Network, running and producing photographic records since 1976, changed over to digital recording in 1986 although the analogue recording is to continue for a while until the data processing system is completed.

Although the new networks have been set up principally to perform a monitoring function, it is expected that data from them will lead to the same advances that have resulted from the data from the Wellington Network, which has provided a clear picture of the uppermost $60 \mathrm{~km}$ of the earth at wellington. In addition, attenuative properties of the earth will be mapped for the first time, and other frequency dependent effects of the earthquakes will be reliably measured routinely.

\section{$3 \quad$ Wave Propagation Modelling.}

The prospect of increasing availability of digital data has lead to an expansion of effort in modelling seismic wave propagation. Two recent areas of advance have been the modelling of long period (1$20 \mathrm{~s})$ body waves of recent, moderately sized New Zealand earthquakes $(M-5.5$ and upwards) to determine the focal mechanisms. Among the earthquakes modelled recently are the two M7 Wairarapa earthquakes of 1942 . The other advance has been in the modelling of shaking effects, from local earthquakes at intermediate distances $(1-10 \mathrm{~km})$. Some 
preliminary results illustrating these techniques have already been published in earlier issues of this Bulletin.

4 Historical Seismicity.

With the possibility of using the new techniques to add to our knowledge of larger historical earthquakes, the Division plans to comprehensively review N.Z.'s historical seismicity over the next five years, to give as complete a description of it as the data from all sources permits.

\section{ENGINEERING SEISMOLOGY}

\section{N.Z. GEOLOGICAL SURVEY, D.S.I.R.}

Earthquake related research projects principally involve the Earth Deformation and Engineering Geology sections, which together constitute the Geotechnical Group of NZGS.

\section{Deformation Mapping}

The mapping of late Quaternary deformation (active faults and deformed marine and fluvial surfaces) is continuing.

\section{$2 \quad$ Geodetic Monitoring}

The geodetic monitoring of crustal deformation is being carried out at some 50 sites.

\section{$3 \quad$ Historical Geodetic Data}

The analysis of historical geodetic data is being undertaken to derive crustal deformation parameters for approximately the last 100 years. This period being one which includes several major crustal earthquakes.

Much of this research was initiated under the Royal Society of New Zealand's Earth Deformation studies programme which coordinated the activities in this field of the DSIR, Lands and Survey, MWD and the Universities, and has been augmented by contributions from overseas workers.

The objectives of the current research projects are:-

1 The improved description of paleoseismicity and its effects through dating both deformation of marine and fluvial terraces and fault displacements. The episodic movements identified have been attributed to major earthquakes. One of the effects of such earthquakes is induced landsliding, currently being documented in the Wellington region along the Wellington fault.

2 The improved understanding of contemporary crustal deformation. The principal technique being utilised for this is the analysis of geodetic data which has enabled description of significant deformation in parts of New Zealand for approximately 100 years.
Collaborative integration of NZGS researchers for investigation of the relationships between crustal deformation kinematics and major earthquakes.

The information obtained by the above projects is utilised in applied projects, such as :-

Seismotectonic hazard assessments of major developments, such as hydroelectric power schemes and major urban areas. These studies integrate geological mapping, Quaternary mapping, geodetic monitoring, and historical and micro-seismicity (in conjunction with the Geophysics Division, DSIR).

2 The promotion of mitigation of fault rupture hazards via the utilisation of simple planning procedures under the Town and country Planning Act.

3 The development of strong motion records related to the earthquake hazards of specific sites, to be used for the dynamic displacements analysis of embankments or slopes (in conjunction with PEL, DSIR.)

PHYSICS AND ENGINEERING LABORATORY, D.S.I.R.

\section{Strong-motion Recording.}

One of the major thrusts of earthquake engineering research at PEL is the operation of the New Zealand strong-motion earthquake accelerograph network and associated research on engineering risk. The primary aim is to collect accelerograms in the epicentral region of major damaging earthquakes to use in developing design spectra. Twenty records of up to $0.19 \mathrm{~g}$ ground acceleration at epicentral distances of between 20 and $60 \mathrm{~km}$ in earthquakes of magnitude 4.8 to 6.0 indicate that $\mathrm{NZ}$ spectra agree well with those predicted by a Japanese response spectra model, but are matched poorly by US models which underestimate the response at short periods. The NZ spectra to date, admittedly from medium magnitude events, are quite different in shape from the much broader band El centro type spectra used in New Zealand design. However, the limited NZ data also shows different behavior to Japanese data in that attenuation of peak accelerations with distance, most clearly demonstrated with records from 12 sites ranging from Murchison to picton in the 1968 Inangahua earthquake, appears much more rapid than in Japan.

A series of spectra for a major $\mathrm{NZ}$ earthquake of magnitude 7 or greater is required to determine the spectral shape in design level shaking and to confirm the Inangahua attenuation with distance. A further area of concern is that recent accelerograms have produced indications of soil layer resonance at several sites with periods ranging from 0.3 to 1.0 seconds. These sites are being investigated by means of vibration tests. 
DEPARTMENT OF CIVIL ENGINEERING, UNIVERSITY OF CANTERBURY.

1 Seismic Hazard Analysis.

Work is continuing on seismic hazard analysis with particular reference to the inclusion of geophysical source models.

2 Ground Rupture.

Theoretical work concerning the application of bifurcation theory to the development of soil rupture surfaces is being carried out. Also being studied is fault rupture diversion and modification caused by the presence of buildings.

\section{Dynamic Soil Properties.}

A set of Californian accelerograph records are being used to study the influence of the dynamic properties of soils.

\section{GEOTECHNICAL ENGINEERING}

\section{MINISTRY OF WORKS AND DEVELOPMENT}

\section{Bridge Abutments.}

In order to obtain a better understanding of the passive earth pressures that develop against bridge abutments built integrally with the superstructure, half size models have been built and tested. The abutments were loaded statically and dynamically by pushing them into sand backfill. The total force and its pressure distribution agreed well with theoretical predictions except at large deformations when the sand was stiffer than predicted. Further tests are being carried out using dense sands.

\section{Pile Foundations.}

Research into the static and dynamic lateral load behaviour is being undertaken as part of a cooperative research programme sponsored by the Road Research Unit. It is expected that this research will permit overseas methods to be evaluated for various $\mathrm{NZ}$ soil types.

DEPARTMENT OF CIVIL ENGINEERING, UNIVERSITY OF AUCKLAND

\section{$1 \quad$ Earthquake Soil-structure Interaction.}

At low levels of earthquake excitation the soil beneath a building foundation behaves elastically. As the severity of the earthquake increases nonlinear deformation becomes increasingly more important. The nonlinearity increases the apparent damping as well as reducing the stiffness of the soil. This project, a continuation of earlier work, is concerned with demonstating the effect of nonlinear soil behaviour on the earthquake response of footings and raft foundations on clay soils.

The major innnovation introduced in the project is the method used to describe the nonlinear footing stiffness. The complexity of finite element modelling is avoided by using an equivalent spring-dashpot approach. The small strain stiffness of the footing is controlled by the elastic properties of the soil. The maximum load the footing can sustain is controlled by the bearing capacity of the soil beneath the footing. Between these two extremes a hyperbolic relationship is assumed.

The research demonstrates the beneficial effect of the nonlinear behaviour of clay soils and the existence of a natural baseisolation effect.

2

Cyclic stress-strain Behaviour of clay soils.

This is a laboratory investigation of the strain-controlled cyclic triaxial behaviour of a small number of natural clay soils. The tests are of the consolidated undrained type and pore water pressures are being measured during the cyclic loading. The purpose of this research is to observe the effect of repeated loading cycles on the stiffness of natural clay soils. This is necessary for two reasons: (i) because data on natural soils, particularly NZ soils, is needed, and (ii) because information on the change in soil properties with cyclic loading is important for the design of foundations to resist earthquake loading. It is well established that when a large number of load cycles is involved, clay soils exhibit a phenomenon of cyclic degradation, a type of fatigue effect. The question is how serious is this for the numbers of cycles involved in an earthquake.

Another aspect of the motivation for the research relates to work that is planned on the lateral load behaviour of piles under earthquake loading. In this situation the effect of the load cycling on the strength of the clay near the top of the pile is of importance as this affects the maximum displacement and bending moment in a pile during an earthquake.

Investigation of In-situ High Strain Dynamic Soil properties.

This project has been carried out to measure the insitu shear modulus and damping factor of soils at high strain. Existing insitu wave propagation techniques, such as the cross hole test, are available to measure the low strain soil proprerties. However, for selsmic response analysis the soil properties at strains approaching 0.01 is required for theoretical studies. High amplitude shear waves were generated and wave forms close to the source were recorded in an attempt to measure the shear wave velocity and rate of strain decay at high strains. While the generation of high strain shear waves was achieved problems were encountered in the analysis of the results. It appears the use of the tradition wave equation is inappropriate close to a shear wave source in a nonlinear medium. Further work is needed to clarify the wave propagation process close to the source. 
against uplift. This is provided either by the presence of return walls that are nailed to the end studs, or by axial

This work concerns the calculation of the deformations and bending moments in pile foundations during earthquakes. The results of recent computer studies have lead to methods appearing in the literature for the calculation of pile deformation during strong ground motion. This study will apply these methods to existing foundations and attempt to gauge the the usefulness of the solutions obtained. The study will also lead to an assessment of the modification of the ground motion by the piles and hence an evaluation of the level of ground motion at the base of the building compared with the free field motion.

DEPARTMENT OF CIVIL ENGINEERING, UNIVERSITY OF CANTERBURY

\section{Retaining Walls.}

Earlier research into the design of retaining walls is continuing with investigations currently under way on rigid walls rotating about the bottom (cantilever walls) or the top (tied-back walls). Passive toe pressure is also being investigated. Limit analysis and small scale model tests are being used. Seismic design parameters for reinforced earth walls are being investigated using larger scale tests on the Department's 20-tonne shaking table. Associated with the work on the walls is a theoretical study of the effects of vertical and lateral motions on the basic Newmark sliding-block model.

\section{Seismic Liquifaction.}

Experimental work is underway to investigate the seismic liquifaction of sands as a follow up to previous theoretical work. Extensive field tests, with special emphasis on dutch and peizocone testing, have been carried out in the Inangahua region where liquifaction occurred during the 1968 earthquake.

\section{STRUCTURAL ANALYSIS AND DESIGN}

\section{BUILDING RESEARCH ASSOCIATION OF N.Z.}

\section{Wall Racking Tests - end restraint conditions.}

The standard P21 racking test is used to determine Bracing Ratings for wall units. The test requires the specimen to be cycled in $1 \mathrm{~mm}$ increments up to $8 \mathrm{~mm}$ lateral displacement. In order to ensure adequate ductility of the component, the wall is racked to a $40 \mathrm{~mm}$ displacement and cycled $+/-40 \mathrm{~mm}$ for four cycles during which the reduction in load is not to exceed $20 \%$ of the peak load.

It has been noticeable from the failure modes of the various wall panels that have been tested to the P21 standard racking test, that a common mode of failure is the separation of the tension chord from the bottom plate. It has long been recognised that in typical house construction braced walls often have additional restraint of gravity loads.

The current work programme attempts to more closely model the actual end restraint conditions within the p2l test. The restraint is provided by a short length of timber nailed to the end stud of the panel and restrained against uplift by a bolted saddle. The end restraint so provided has the flexibility of the nails in shear.

As anticipated from the performance modes observed, the provision of end fixity effects the behaviour of the panel quite markedly. The panels tested to date (Gibraltar Board) have significantly higher initial stiffness, but degrade during the high displacement cycling, indicating less ductile performance.

\section{Profiled Sheet Metal Diaphragms.}

The objectives of this research programme is to develop design and testing methods which would enable the strength and stiffness of profiled sheet materials, used as cladding to buildings, to be taken into account in the structural design.

It is anticipated that the project will result in the preparation of design information for such structures which will be made available to the industry in both published and electronic form. The first part of the project, involving a literature survey, is almost completed.

3 Racking Resistance of External Flush Glazing.

The increasing use of high modulus silicone sealants with good weathering resistance, satisfactory performance over a wide temperature range, and with load-bearing capabilities has resulted in the increasing use of structural silicone glazing systems where the glass is partially or fully supported by a sealant.

The objective of this research project is to gain an understanding of the ability of such external flush glazing to withstand racking. The mode of failure and the behaviour of this glazing system compared to traditional channel and gasket glazing will be determined by laboratory testing of suitable representative samples.

\section{$4 \quad$ Fire Rating of Seismic Gaps.}

The necessity to separate buildings and/or components of different dynamic characteristics has been a feature of seismic design for a long time. The gaps between the structures vary in size and form depending upon the required separation, the location of the joint, and the normal operation of the joint.

The objective of the research programme is to prepare guidelines for the designer of appropriate means of ensuring fire resistance of seismic gaos. The project has recently commenced and information is being sought from designers of details of the 
various forms of seismic joints that are being detailed and the widths of the separations and operational requirements of the joint.

\section{MINISTRY OF WORKS AND DEVELOPMENT}

1 Timber Engineering.

Research is being concentrated on short term seismic effects using $\mathrm{NZ}$ grown timber to complement overseas research that generally concentrates on the long term behaviour of timber and its connections.

The results of a number of tests on Pinus Radiata and Douglas Fir using a variety of common timber connectors are being collated with a view to making recommendations for design code changes.

Recent tests investigating the seismic response of four ply-box portal frames showed them to be more flexible than simple theory predicts. One conclusion is that nail deformation must be allowed for in both the members and the joints in order to obtain realistic estimates of deflections. Since the portals were still behaving elastically at an interstorey drift of $2.5 \%$, the seismic design needs to assume an elastic response with the design being governed by deflection.

Data for the establishment of more appropriate seismic loads (i.e. SM factors) for diagonal timber bracing acting in both tension and compression have also been compiled from the results of dynamic testing.

\section{Strengthening and Evaluation of Existing Buildings.}

It is often desirable, for either economic or historical reasons, to retain existing brickwork when strengthening older buildings. MWD is continuing to review strengthening threshold limits and search for economic means of strengthening brick and concrete buildings. Spraying premixed GRC to brickwork using a peristaltic pump is being investigated to speed up the current slow hand application method. Tests are also being carried out to develop a method of forming "cold" joints in GRC to overcome the present limitation of permitting construction joints only at the top and bottom anchorages as at present. Recent tests on the base connection of GRC faced walls has lead to a re-evaluation of earlier conclusions regarding the "limited ductility" of such walls loaded in their plane. It now appears that most of the apparent ductility was in the connections and that the GRC faced walls themselves are quite brittle.

Dynamic testing overseas has shown that unreinforced masonry of certain height to thickness ratios can be stable under high intensity face loading. MWD is currently carrying dynamic wall tests to evaluate the effects of NZ materials and other parameters, such as the absolute wall thickness, to see if the need to provide backing to such walls can be eliminated. The dynamic testing will also be used to establish computer model parameters to predict the performance of face loaded brick walls during earthquakes.

The economic use of steel strip and nails as a successful jointing method for particle board sheets used as a strengthening overlay to existing tongue and groove floor diaphragms has been demonstrated by testing.

Recent work overseas suggests that the seismic performance of existing masonry buildings may be reduced if the floor diaphragms are strengthened above a certain strength level which is lower than current code requirements. Samples of existing $T$ \& $G$ floors have been obtained for static and dynamic testing to determine the applicability of this overseas research to NZ construction and materials.

MWD is continuing its programme of insitu testing of old brickwork in order to build a data base that will enable local masonry properties to be evaluated and the relevance of overseas research to be determined.

The seismic performance of frame buildings built without the joint shear and confining reinforcement required by current codes is not readily predictable. MWD has embarked on a a series of tests to obtain a better understanding of how these buildings, which form a sizeable proportion of our building stock, will behave in an earthquake. This will permit a rational evaluation of such buildings and an improved assessment of life and property risk.

3 Construction Inovations and Problems.

The trend towards using precast structural elements has led to a number of details involving onsite grouting. MWD has recently carried out preliminary tests to determine the shear strength of grouted horizontal joints and anchorage strength of column reinforcement grouted into prestressing ducts. It is intended to follow these tests with tests on full scale joints such as have been used in a number of buildings.

Periodically there have been reports of reinforcing bars failing at bends during construction, possibly due to strainage embrittlement. These failures have generally occurred as a result of shock loading and concern has been expressed about the likely seismic performance of the bars. Test to date on prestrainaged bars at likely earthquake strain rates have not resulted in any bar failures.

PHYSICS AND ENGINEERING LABORATORY, D.S.I.R.

\section{Base-isolation.}

The Laboratory has pioneered the practical application of the base-isolation approach to earthquake-resistant design. As a result, a number of base-isolated structures inspired by New Zealand work are now completed or underway in the USA, Japan and Italy, with considerable interest being shown in china as well. PEL is currently involved in the design, manufacture and testing of lead-extrusion dampers for the 
new Wellington Central Police station which is a critical facility that is required to be operational after a major earthquake. Consideration is also being given to the protection of machinery and equipment vulnerable to earthquake vibration, and a preliminary series of tests has been performed on very flexible laminated rubber bearings suitable for low vertical loads which have been proposed for the isolation of electrical switchyard equipment.

DEPARTMENT OF CIVIL ENGINEERING, UNIVERSITY OF AUCKLAND

\section{Hysteretic Response of Reinforced Concrete structures.}

The first part of this project involved carrying out a series of single degree of freedom analyses of structures with different structural characteristics to see how these influenced ductility and energy dissipation requirements under seismic conditions. The different models used were elastic, elasto-plastic, bilinear with $10 \%$ strain hardening, and a shear stiffness degrading model. The second part involved testing a reinforced concrete beam-column joint.

2 Behaviour of Timber Brick Veneer Walls Under Cyclic Loading.

A series of timber and timber with brick veneer walls with and without window openings have been subjected to cyclic loading to assess the influence of the veneer on the seismic performance. Current work in this project involves testing the ties, which are used to hold the brickwork to the timber, under cyclic conditions with and without axial load.

3 Moment Redistribution in Seismic Resistant Concrete Frames.

Under seismic conditions extensive redistribution of gravity actions occurs as soon as the first plastic hinges form in the structure. The significance of this redistribution on the seismic performance of frame structures is being investigated in a series of static and dynamic analyses.

4 Seismic Response of a Base-Isolated Bridge.

The acceleration time histories recorded from the snap-back tests on the Mangatewai-iti bridge are being processed to determine the nonliear dynamic behaviour of the bridge. Digital filtering of the records has been found to be most effective in establishing the predominant 'modes' and 'frequencies' of the bridge. Presently, displacement time histories are required so that force/displacement relationships for the bridge bearings can be obtained. The accuracy of these depends upon a reliable base-line correction method being obtained.

Further targets of the project involve bridge model development for earthquake simulation and design recommendations. Two bridge models will be established. One will be used in earthquake simulation to study the bridge behaviour under different excitations. The other, an equivalent static model, will be developed with the prior knowledge of the bridge behaviour and used for design recommendations.

5 Large Displacement Inelastic Analysis of Thin-walled Beams Under Cyclic Loading.

A conventional thin-walled beam model has been extended to include shear strains, local deformations, inelastic materials and large displacements. Elements are modelled as assemblages of rectangular plates with bi-cubic local buckling displacement fields. Displacements due to beam axis deformations are obtained from a second order treatment of the cross-section rotations. The problems arising from the non-commutative property of rotations about fixed axes are overcome by using the semitangential definition of moments and rotations. A total Lagrangian formulation is used to derive the finite element matrices.

The element has been incorporated into the ANSR III structural analysis program and is being used to study the performance of steel I beams under cyclic loading in the post-buckled and post-elastic regimes.

\section{Energy Dissipators in Cross-braced} Frames.

An analytical model has been developed for the nonlinear response of concentrically braced frames containing energy dissipators at the brace intersections in the form of rectangular, flexurally yielding rings. An accompanying tests program has verified the analytical model and provided further evidence of the stable hysteretic response of these simple devices. A design procedure has been formulated and a computer program written to facilitate the process.

DEPARTMENT OF CIVIL ENGINEERING UNIVERSITY OF CANTERBURY

1 Dynamic Structural Response.

Several analytical investigations involving the dynamic response of structures to earthquake excitation are being conducted. Two studies are using the time-history computer program "Ruaumoko" to study the response of building and bridge structures mounted on flexible bearings, for example lead-rubber devices, subjected to severe earthquake motions. In particular the deflections, equivalent viscous damping, substructure forces, structural ductility and period shifts are being studied. The aim is to further develop seismic design procedures for such base-isolated structures. Computer analyses are also being used to study the effects of soilfoundation compliance on the inelastic response of frames to seismic excitation in order to develop suitable compliance models for finite element and boundary element analyses to represent radiation damping a well as uplift and other non-linear effects. The failure probability of multistoried reinforced concrete buildings, subjected to various types of earthquake loading input and distributions of dead load, live load and moments of resistance of members, is also being studied by computer simulation. 
Extensive experimental and theoretical investigations into the behaviour of reinforced and prestressed concrete structures subjected to earthquake type loading have been conducted and are continuing. In the area of bridge structures, one study is attempting to quantify the influence of design assumptions on the inelastic response of flexurally responding reinforced concrete bridge piers. Experimental work will involve shake-table testing to investigate the response of slender piers, and to check the influence of foundation flexibility on the response. Tests and analyses are being conducted to study the available ductility of reinforced concrete columns containing non-standard details for transverse reinforcement, such a $90^{\circ}$ hoop hooks and cross-ties with tension splices that are currently not permitted in New Zealand. The use of interlocking spirals for transverse reinforcement will also be investigated. An experimental and theoretical investigation of the shear strength of circular reinforced concrete bridge columns subjected to biaxial lateral earthquake excitation is also being carried out. static and dynamic (shake-table) tests are being conducted, with the theoretical analyses concentrating on establishing realistic test regimes.

3 Reinforced Concrete.

In the area of reinforced buildings, tests and theoretical studies of beam-column joints, including the presence of slabs, are being conducted as part of a United States / New Zealand / Japan / China collaborative research project. Three fullscale beam-column-slab subassemblages are being constructed and tested at the University of Canterbury and at laboratories in each of the other countries, to investigate differences between the seismic design approaches of the reinforced concrete codes of the four countries. Also being studied is the limited ductility design of reinforced concrete building frames for earthquake loading, initially by conducting tests on reinforced concrete columns with limited quantities of transverse reinforcement and theoretical analyses leading to a design equation which relates the quantity of transverse confining steel to the available curvature ductility and the other variables. A related series of tests is being carried out on reinforced concrete beam-column joints designed for limited ductility. Reinforced concrete shear walls designed for limited ductility have been tested and analysed in order to investigate possible less ductile inelastic failure mechanisms of walls.

\section{$4 \quad$ Prestressed Concrete.}

A study on the use of partially prestressed concrete for offshore concrete towers is being completed. This project has involved an investigation of the dynamic response of such towers subjected to earthquake shaking, including the effects of soil- structure-water interaction and laboratory test analyses of tubular members to investigate available strength and ductility. Another project drawing to completion has studied the seismic performance of prestressed concrete piles, involving tests and analyses of the strength and ductility of such piles and of pile-pilecap connections with various reinforcement details.

\section{$5 \quad$ Structural steel.}

The use of structural steel for building structures is being researched using computer analyses to develop capacity design procedures for moment resisting, eccentrically braced and concentrically braced steel frames subjected to seismic excitation. An experimental and theoretical study of the performance of steel-encased concrete piles under longitudinal compression/tension loading, under combined axial load and inelastic lateral bending, and under simulated seismic loading in a sand-foundation tank has just been completed.

\section{Timber Structures.}

In one research project, the response of timber structures subjected to seismic loading is being studied with special emphasis om plywood sheathed shear walls. This investigation has involved static and shake-table tests of walls with a range of nail patterns and other details, along with dynamic computer analyses that include the effects of realistic hysteretic loop shapes to evaluate design strength ratings. Another project is investigating the likely earthquake performance of a range of lowrise timber structures using dynamic analyses to provide time-history information. Differing hysteresis loops are being modelled and the response to a range of different earthquake records, both natural and artificial, is being studied.

\section{$7 \quad$ Masonry Shear Walls.}

An investigation of the contribution of flanges of reinforced masonry shear walls to strength and ductility is underway.

\section{Low Strength Masonry.}

Traditional earth and low-strength masonry construction techniques in various areas are being studied together with their observed seismic behaviour with a view to recommending modifications to improve their seismic performance. 
APPENDIX A

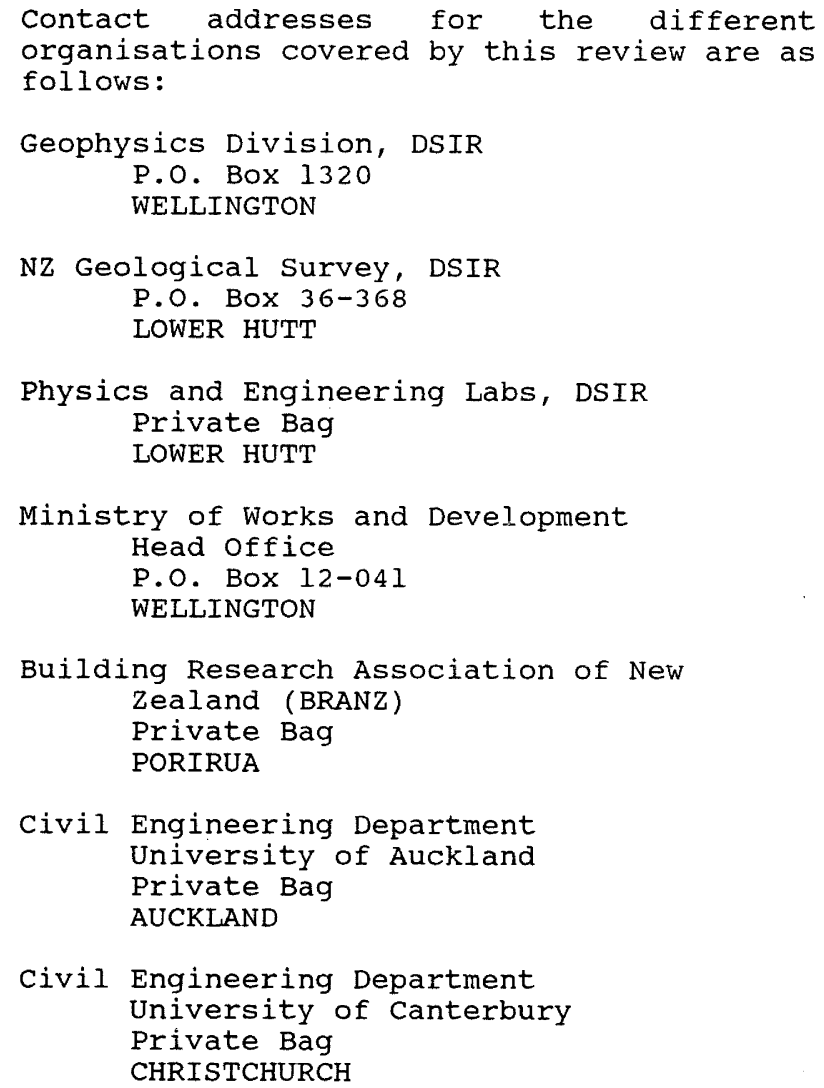

Civil Engineering Department University of Auckland Private Bag AUCKLAND

Civil Engineering Department University of Canterbury Private Bag CHRISTCHURCH 